${ }^{2}$ Van Royen, E. A., Ten Cate, J. W. (1973). Lancet, 2,449 .

Enzyme Analysis using the Vitatron 'Automatic Kinetic Enzyme System'

P. O'GORMAN, SHANTA PATEL, AND VALERIE A. PARSONS (Brook General Hospital, London, and Greenwich District Hospital, London) The Vitatron 'automatic kinetic enzyme system' is a new instrument for automated discrete enzyme analyses by the kinetic method. It possesses the advantages of variable reaction temperature, small sample of neat serum, and automatic calculation of activity with printout of results.

The apparatus has been tested according to the scheme for evaluation of instruments for automatic analysis (J. clin. Path., 1969, 22, 278) under routine laboratory conditions for a series of commonly requested enzymes.

Results of these assays have been compared with those from the existing routine methods and the delivery of two instruments to neighbouring hospitals has enabled comparison of instrument performance.

\section{Electron Microscopical Investigation on Intravascular Coagulation in the Human Renal Glomerulus}

J. H. SCHUURMANS STEKHOVEN AND U. J. G. M. VAN HAELST (Institute of Pathology, Laboratory of Electron Microscopy, University of Nijmegen, The Netherlands) Out of a total of 230 renal biopsies, studied by electron microscopy, intravascular coagulation was found in 67 biopsies $(29 \%)$ performed in 58 patients. Of these 67 biopsies, 31 were taken from 24 patients with a transplanted kidney and 36 from 34 patients with various glomerular diseases. In 38 out of the 67 biopsies aggregates without distinct cross striation are found in varying numbers in the capillary lumina of the glomeruli. Real fibrin, ie, with cross striation, was found in eight cases; three different forms could be distinguished. In the remaining number of the cases, the capillary lumen is filled partly or completely with material which shows a great diversity of its ultrastructure; this material has a light floccular or dense aspect. Disintegrating erythrocytes, macrophages, remnants of endothelial cells, and sporadically some thrombocytes can be found in this material. In these cases the normal endothelial lining of the basement membrane has partly or completely disappeared.
By comparative study of sequential biopsies we shall try to answer the question if and to what extent the morphological aspects of intravascular coagulation change with time.

\section{Intravascular Coagulation and Pregnancy}

JOHN BONNAR (Department of Obstetrics, Radcliffe Infirmary, Oxford) Extensive changes occur in the coagulation and fibrinolytic systems during pregnancy, particularly in the third trimester. The concentration of plasma fibrinogen, factor VIII, factors VII and X substantially increases and plasma fibrinolytic activity markedly decreases. During childbirth changes in keeping with activation of the clotting mechanism take place and fibrinolytic activity returns to normal after delivery of the placenta. The changes in the haemostatic systems in pregnancy may be a physiological development to preserve the integrity of the maternal and fetal circulations during pregnancy and to facilitate haemostasis in the uterus during and after separation of the placenta. These alterations also establish a vulnerable state for intravascular coagulation.

In conditions such as abruptio placentae and amniotic fluid embolism massive intravascular coagulation can develop leading to defective haemostasis with depletion of clotting factors and release of large amounts of fibrin degradation products into the circulation.

A low-grade process of intravascular coagulation also occurs in pre-eclampsia. The disturbance of the balance between clotting and fibrinolysis in pre-eclampsia seems to be localized to certain areas of the vascular tree, particularly the uterus and kidney. Thrombotic occlusion appears to contribute to the impairment of placental blood flow and the development of placental infarction and ischaemia which occur in pre-eclampsia and in pregnancies complicated by impaired fetal growth. In pregnancies complicated by severe placental insufficiency treatment with heparin and dipyridamole improved placental function and fetal growth.

Further knowledge of the physiology and pathology of the coagulation and fibrinolytic systems may open up a new field of rational treatment for several of the hazards inherent in pregnancy.

\section{Mycoplasmas and Human Infertility?}

J. DE LOUVIS, M. BLADES, R. HARRISON,

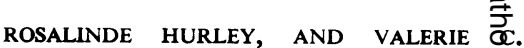
STANLEY (Queen Charlotte's Matern̈̈̈ty Hospital, London) There have be reports that eradication of $T$-strizin mycoplasmas by appropriate antibiotifs has been followed by pregnancy in coup adjudged infertile. The authors are en ged in studies of the incidence of $M y$ plasma hominis and $\mathrm{T}$-mycoplasmas औैn infertile and fertile couples, preliminary to a double-blind controlled trial of doxycycline in the treatment of infertility unascertained cause. One hundred aợ twenty infertile couples and 36 fer商e couples are the subjects of the studies \$No far conducted.

The criteria of infertility, and the materials and methods used, the sifes sampled, and the incidence of $M$. homints and T-strain mycoplasmas will be reportêd.

A Case of Carcinosarcoma of Ureter $\stackrel{-}{\longrightarrow}$ H. B. MCDADE, E. M. ARMSTRONG, AND A. \&. GRAHAM, (Departments of Pathology a d Urology, Western Infirmary, Glasgow) Carcinosarcoma of ureter is an extremely rare neoplasm of which only one previouts case has been described in the literature. The patient in the present case is a year-old retired general labourer w命 presented in December 1971 complainimg of haematuria and some colicky abdorfinal pain. Repeated cystoscopic examira tions showed no significant patholo $\overline{\bar{g} y}$ until January 1973 when a necrotic friaße tumour mass was seen exuding from the R ureter. A R uretero-nephrectomy wäs performed in February 1973 and showed that the tumour was arising at the junction of the middle and lower thirds of ureter and extended as a $1 \mathrm{~cm}$ diameter stalk of material down to the ureteffc orifice. Histological examination revealed an intimate admixture throughout the tumour of both malignant epithelial and malignant stromal elements. After \& initially good postoperative recovery the patient presented again in May 1973 with a recurrence of symptoms and examination revealed a recurrence of tumour in the region of the $\mathbf{R}$ ureteric orifice. This wests removed and the site thoroughly treated with diathermy. The patient has remained symptom free and in good health since then with no cystoscopic evidence of recurrence. The diagnostic difficulties and pathogenesis of this neoplasm will the discussed.

Immunological Aspects of Hepatobiliary Disease

A. MILFORD WARD, G. ELLIS, AND D. স্ণ. 